\title{
Pollen Viability of Aeschynanthus tricolor Hook.
}

Vitri Garvita Gandadikusumah*, Hary Wawangningrum, Sri Rahayu

Center for Plant Conservation, Bogor Botanic Gardens, Indonesian Institute of Sciences, Bogor, Indonesia

\section{ABSTRACT}

Aeschynanthus (Gesneriaceae) is climbing or trailing epiphytes from the tropical forests of South-East Asia. Several species are widely cultivated for their attractive flowers, which usually scarlet with long corolla tubes and probably bird pollinated.This study was carried out on Aeschynanthus tricolor Hook. to determine in vitro germinability of (1) pollen collected from flowers at anthesis, on the day before anthesis, or up to five days after an thesis and (2) pollen collected on the day of anthesis and then stored at $-20^{\circ} \mathrm{C}$ for 127 days. Germinability tests were carried out on pollen grains after stored for four hours in $10 \%$ sucrose solution. The highest in vitro germination percentage observed was pollen collected on the day of anthesis (96.3\%) and the lowest was pollen collected on the fifth day after anthesis (5.6\%). The germination percentage of pollen after stored at $-20^{\circ} \mathrm{C}$ was $98 \%$ at beginning and $22 \%$ after 127 days. From this research we can conclude that pollen of $A$. tricolor can be successfully collected and then stored for some time, will be practical benefit for plant breeding and conservation purposes.

Keywords: Aeschynanthus tricolor, pollen germinability, storage, in vitro, sucrose

\section{INTRODUCTION}

Aeschynanthus, an epiphytic genus with 160 species, is widely spread in Southern China and Southeast Asia to New Guinea and The Solomon Islands[1]. Aeschynanthus is includedin Gesneriaceae and subfamily Didymocarpoideae. In1823, Jack described Aeschynanthus volubilis Jack and Aeschynanthus radicans Jack for the first time, which are both from Sumatra [2]. The first specimens of Aeschynanthus tricolor Hook. were founded in Borneo [3]. The common name for species of the genus is "lipstick plant", which comes from the appearance of the developing buds. $A$. tricolor Hook. is known as the special lipstick flower. Different to others, $A$. tricolor has campanulate calyx and short corolla tube, with dark red coloration. The special striped coloration is formed along the outer side of corolla tube; a characteristic which is retained in its hybrid crosses[3].

Aeschynanthus tricolor is perennial woody subshrub, epiphytic but sometimes lithophytic in the wild. The stems are branching. The leaves are opposite, usually thick and leathery, bright to dark green adaxial

\section{${ }^{*}$ Corresponding author:}

Vitri Garvita Gandadikusumah

Center for Plant Conservation, Bogor Botanic Gardens,

Indonesian Institute of Sciences

Jalan Ir. H. Juanda No. 13, Bogor 16003, Indonesia

E-mail: gandadikusumahvitri692@gmail.com and much paler sometimes purple-flushed abaxial. Infloresences arise from leaf axes towards or at tips of branches. A tricolor flowers are strongly protandrous, which means that male (androecium) and female (gynoecium) organs mature separately. The male organ matured when the flower is anthesis, and the female organ matured five days after the male organ matured [3]. The development of flowers take 32 days from the beginning of a flower bud until anthesis. The habit varies from stiff and twiggy to pendent and trailing, or creeping and rooting at the nodes [3, 4].

If we wish to use this strongly protandrous flower as a potential male parent in the development of hybrids, knowledge of pollen viability will be useful for breeding purposes and for conservation as well. The problems for breeding arise when two species or varieties intended for hybridization were not bloom at the same time. In such cases, pollen from the potential male parent will need to be stored until the time when gynoecium of potential female parent is receptive. We therefore want to understand, the best time to harvest pollen for storage, and how long will pollen remain vi-

How to cite:

Gandadikusumah VG, Wawangningrum H, Rahayu S (2017)

Pollen Viability of Aeschynanthus tricolor Hook. J. Trop. Life. Science 7 (1): $53-60$. 
able under basic storage condition. Knowledge regarding pollen storage and viability of this species will also be useful for conservation purposes, as this species is rarely found in the wild, and up to now has only been found in Borneo. As its habit is epiphytic, the growing conditions for the species require another supporting tree as a host (phorophyte) and nowadays we're facing severe deforestation in its native environment. Pollen storage is one of methods to conserve plant's germplasm [3].

Pollen of several Aeschynanthus species were studied by Luegmayr in 1993 in acomparative study of Old World Gesneriaceae. He suggested that pollen possesses characters of taxonomic relevance at genetic level. Burt \& Woods in 1975 noted that flowers of Aeschynanthus mostly have a syndrome of characters associated with bird pollination [2].

The potential yield of viable pollen collected from the field is influenced by season and timing of flowering, quantity of pollen set, and method of handling and storing pollen. There are many particular factors that determine pollen availability, such as genetic controls, temperature and moisture, collecting time, radiation, chemicals applied to plants for insect control, and industrial waste gasses. Low or high temperatures during the development period can adversely affect the quantity and germination response of mature pollen. Pollen isolated in early morning germinates better than that collected at other times of the day. This is probably related to metabolic transitions and moisture stresses. Many factors also affect the viability of pollen in storage [5].

The amount and quality of pollen produced by a flower are important components of fitness. The quality of pollen is assessed on the basis of viability and vigour of the pollen grain (the proportion of pollen grains that are viable). Pollen vigour refers to the speed of germination of pollen grains and rate of pollen tube growth. There are four phases in pollen germination and tube growth: imbibition phase, lag phase, tube initiation phase and rapid tube elongation phase [6]. Pollen of many species can be stored at temperatures between $4^{\circ} \mathrm{C}$ and $-20^{\circ} \mathrm{C}$ for the short term [7]. The life span of pollen grains has been reported both in in vitro and in vivo germination tests as lasting for a few minutes up to several days $[8,9]$.

The viability of pollen has been investigated in terms of its contribution to compatibility and fertility for crop improvement and breeding projects. Several studies also assessed pollen viability by staining and direct count [10]. Commonly, in vitro pollen germina- tion tests have been used to determine pollen germination percentage and can be used for assessing pollen vigour by monitoring germination rate over a period of time, or by measuring the length of pollen tube formation. Most pollen viability tests germinate small samples of pollen and observed under microscope to count grains percentage of producing tubes over time. Several replicates may be tested and germination percentage is taken asan index of pollen viability.

The main problem with in vitro germinationis to find suitable testing medium for each cultivar. Many pollen grains can germinate in water or aqueous solutions of sucrose with no additives, but pollen types such as tri-nucleated grains need special substrates for germination because tri-nucleated grains have abnormally short pollen tubes and reduced to protuberances. Sucrose is the best carbohydrate source for pollen germination and tube growth for most plants. Under natural conditions, pollen of different species often require specific media for germination [6, 11]. The liquid medium of Brewbaker and Kwack is usually used in current protocols for pollen germination $[6,12]$.

Research on pollen germination using different media has been carried out on a wider range species. For example, pollen from five Iranian Apricot cultivars was tested using a medium made up of $15 \%$ sucrose, 100 ppm boric acid and $0.5 \%$ agar. The range of germination was $20-54 \%$, and 24 hours culturing was enough to obtain maximum germination [13]. Similarly, in vitro pollen germination of Tribulus terrestris was studied with different concentrations of sucrose solution $(10,15,20$ and $25 \%)$ alone and in combination with $0.01 \%$ boric acid. The percentage of pollen germination was less in sucrose alone; when boric acid was added to the medium, the percentage increased [6].

In vitro germination tests have often been performed to evaluate the duration of pollen viability and the ability of aged pollen to produce fruits and seeds containing embryos; also to determine the effectiveness of pollen storage procedures. For breeding programmes and genetic conservation, pollen grains often have to be stored in freezers for extended period of times. Thus, our research on $A$. tricolor aimed at studying pollen viability during anthesis and after storage in a freezer at $-20^{\circ} \mathrm{C}$, employing in vitro germination tests.

\section{MATERIALS AND METHODS}

The study was conducted in January - August 2015 at Treub Laboratory, Centre for Plant Conservation Bogor Botanical Gardens. 


\section{Source of pollen samples}

Two parental plants of $A$. tricolor Hook. that had been collected from Central Kalimantan, Indonesia in 2000 were grown out in a greenhouse. Careful observations were made of flower development to identify the stage of first anthesis. Pollen samples were taken from a total of 30 flowers that bloomed on the two parent plants.

\section{Experiment 1: Viability of pollen at and around the time of anthesis}

Pollen samples were taken from fresh flowers at various defined stages of flower development, at and around the time of anthesis: on the day before anthesis (H-1); on the day of anthesis (Ho); on the first day after anthesis $(\mathrm{H}+1)$; on the second day after anthesis $(\mathrm{H}+2)$; on the third day after anthesis $(\mathrm{H}+3)$; on the fourth day after anthesis $(\mathrm{H}+4)$; and on the fifth day after anthesis $(\mathrm{H}+5$, the day of flower drop).

On each sampling day, between 07.00 and 07.30 AM, pollen was collected with pointy tweezers from three separate flowers. The fresh pollen grains from each flower were placed into $10 \%$ sucrose solution in separate petri dishes and left to stand at room temperature for four hours. Then drops of the pollen/sucrose solution from each dish were distributed evenly on microscope slides and cover slips were placed on top. For each flower three separate slides were prepared in this way, making a total of nine slides on each sampling.

Scanning optical microscope was used to observe pollen grains in five randomly chosen fields of view per slide at $100 \times$ magnification. The number of non-germinated pollen was counted in each field of view, as well as the number of germinated pollen. A pollen was germinated, if the emerged pollen tube had reached a length twice of pollen grain diameter [14], citing Gupta et al. (1989)].

The percentage of germinated pollen on each slide (with three replicate slides for each pollen sample) was calculated as follows $[6,15]$ :

germination $(\%)=\frac{\text { germination number of pollen }}{\text { total pollen per field }} \times 100 \%$

An analysis of variance (ANOVA) was carried out using Statistics for Agricultural Research, IRRI (STAR) to test whether significant differences in germination percentage founded between seven pollen sampling occasions $(\mathrm{H}-1$ to $\mathrm{H}+5)$.

\section{Experiment 2: Pollen viability after storage}

Pollen samples collected on the day of anthesis (Ho) from several flowers were mixed in a microtube sized $1.5 \mathrm{~mL}$. The microtube was then stored in aclosed jar containing silicagel and placed in afreezer at temperature $-20^{\circ} \mathrm{C}$. Viability of this pollen was tested on the day of storage (before storing), then 7 days after first storage, 14 days after storage, 21 days after storage, 28 days after storage, two months after storage and three months after storage.

The procedure for testing germinability was the same as in experiment 1 ; i.e. pollen samples from the freezer were mixed with $10 \%$ sucrose and left at room temperature for four hours before drops were taken and placed on amicroscope slide for counting. Three slides per sample were observed and five fields of view were counted. Germination percentages were calculated according to the formula above $(1)[6,15]$.

\section{RESULTS AND DISCUSSION}

The general pattern of flower development at and around the time of anthesis in A. tricolor is shown in Figure 1, and can be used as a guide for cross pollination in the species. Based on our previous studies [3], flower development takes 32 days from the beginning of a visible flower bud until anthesis. The anthesis take place about six days, with the maturation of pollen at the first day until fourth days of blooming before the maturation of stigma, the anther already wilted. The stigma matured 5 days after the anther matured and become wilted.

When pollen taken from developed flowers is tested for germinability, non-germinated pollen usually shows poor tube growth and is likely to be ineffective in achieving fertilization. In Figure 2, pollen tube formation of $A$. tricolor (A) is contrasted with non-germinated pollen without pollen tube growth (B). In our experiments, we regarded a pollen grain to be viable if the length of pollen tube exceeded twice the diameter of pollen grain [14].

\section{Experiment 1, Effect of the stage of floral development on viability of pollen}

The time of pollen collection significantly affected its germination percentage (Table 1). The percentage of pollen grains that developed healthy pollen tubes after four hours in $10 \%$ sucrose solution was highest in pollen takenat anthesis [Ho], and the lowest in pollen taken five days after firstanthesis $[\mathrm{H}+5]$. The pollen grains collected one day before anthesis $[\mathrm{H}-1]$ showed 
Table 1. Percentage of pollen germination of $A$. tricolor in $10 \%$ sucrose solution

\begin{tabular}{cccccccc}
\hline Days & $H-1$ & $H O$ & $H+1$ & $H+2$ & $H+3$ & $H+4$ & $H+5$ \\
\hline Pollen germination & $72.3 \% \pm 0.2^{\mathrm{b}}$ & $96.3 \% \pm 2.1^{\mathrm{a}}$ & $93.1 \% \pm 5.4^{\mathrm{a}}$ & $83.1 \% \pm 20.7^{\mathrm{ab}}$ & $71.1 \% \pm 36.2^{\mathrm{b}}$ & $7.1 \% \pm 9.6^{\mathrm{c}}$ & $5.6 \% \pm 9.1^{\mathrm{c}}$ \\
\hline
\end{tabular}

Note: Values followed by the same letter do not differ significantly $(\mathrm{p}<0.05 \%)$

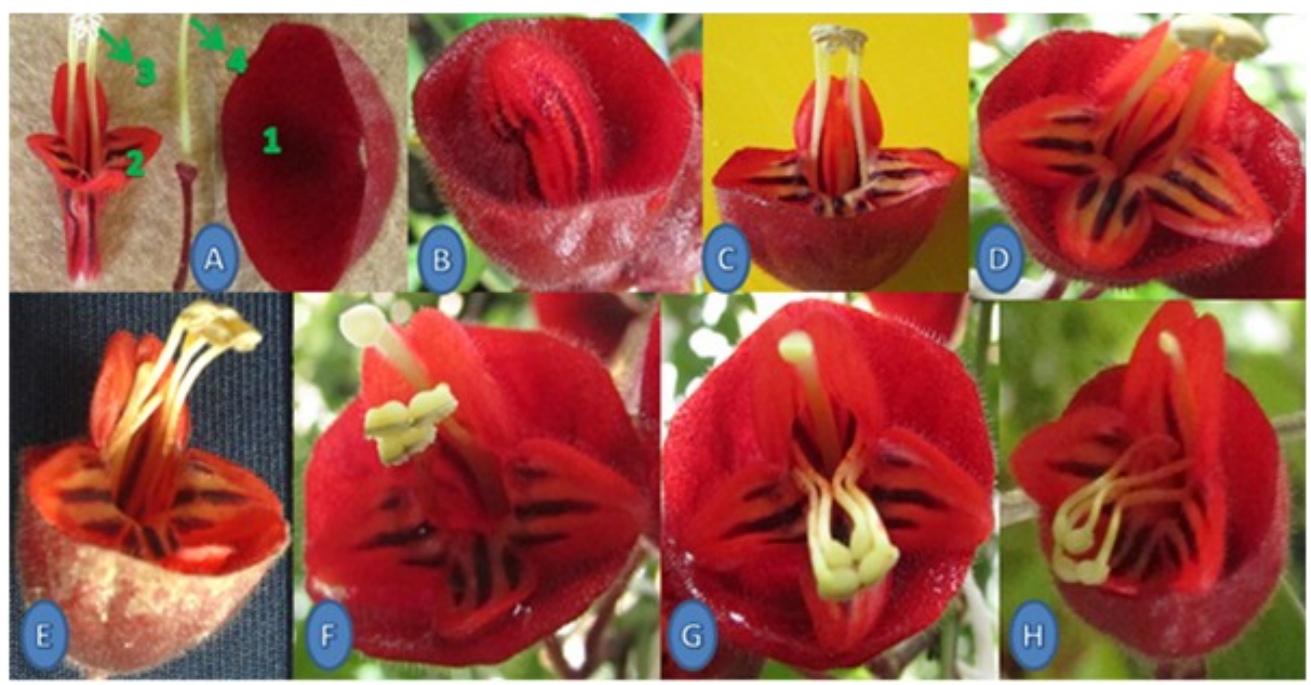

Figure 1. Period of anthesis in A. tricolor Hook. (A) flower parts; 1. calyx, 2. corolla, 3. anthers, 4. stigma, (B) H-1, (C) Ho, (D) $\mathrm{H}+1$, (E) $\mathrm{H}+2$, (F) $\mathrm{H}+3$, (G) $\mathrm{H}+4$, (H) $\mathrm{H}+5$

$72.3 \%$ germination percentage compared with $96.3 \%$ for pollen collected on the day of anthesis [Ho]. Four day after anthesis $[\mathrm{H}+4]$ and five days after anthesis $[\mathrm{H}+5]$ the percentage germination had dropped to $7.1 \%$ and $5.6 \%$ respectively.

\section{Experiment 2. Effect of extended pollen storage on its viability}

The germination percentage of pollen mixed from several flowers on the first day of anthesis (Ho) and then tested for germinability after four hours in $10 \%$ sucrose solutionwas $98 \%$. However, germination percentage of samples from the same pollen batch stored at $-20^{\circ} \mathrm{C}$ in a $10 \%$ sucrose solution for 127 days dropped down to $22 \%$. The germination was observed to decline progressively with storage duration up to 127 days (Figure 3).

Aeschynanthus flowers are known to beprotandrous, which means the male organs (androecium) reach maturity before the female organs (gynoecium); at the time when the stamens wither and droop, the gynoecium rapidly elongates. This condition together with corolla shape and the presence of nectar indicates that its pollinated by birds in the wild. There is no studies have discussed the factors that affected protandrous, but it is based on genetic factors of those species. Pollination in nature was helped by insects or birds. Hummingbirds, pollinator bird, will casually visit flowers in search of food. Birds collect nectar at the base of hanging or pendant flowers, pollen will stick on bird head, and when the bird is perched on a ripe female flower, pollen in a bird's head will gets stuck onto the stigma.

For plant breeding purposes using hybridization techniques, pollen will need to be collected and stored until the time when the gynoecium of the potential female parent is receptive.

\section{Viability test of pollen collected at anthesis}

Our results of $A$. tricolor showed that anthesis is the best time to collect pollen because it gives the highest germinationpercentage. Five days after anthesis is not recommended for the collection of pollen because very few pollen grains germinate at this late stage of collection.

In our experiments we used $10 \%$ sucrose solution for the in vitro germination. A range of studies with various plant species suggests that such concentration of externally supplied sucrose maintains an appropriate osmotic balance and acts as nutritional source for pollen metabolism.

The important external factors influencing pollen 


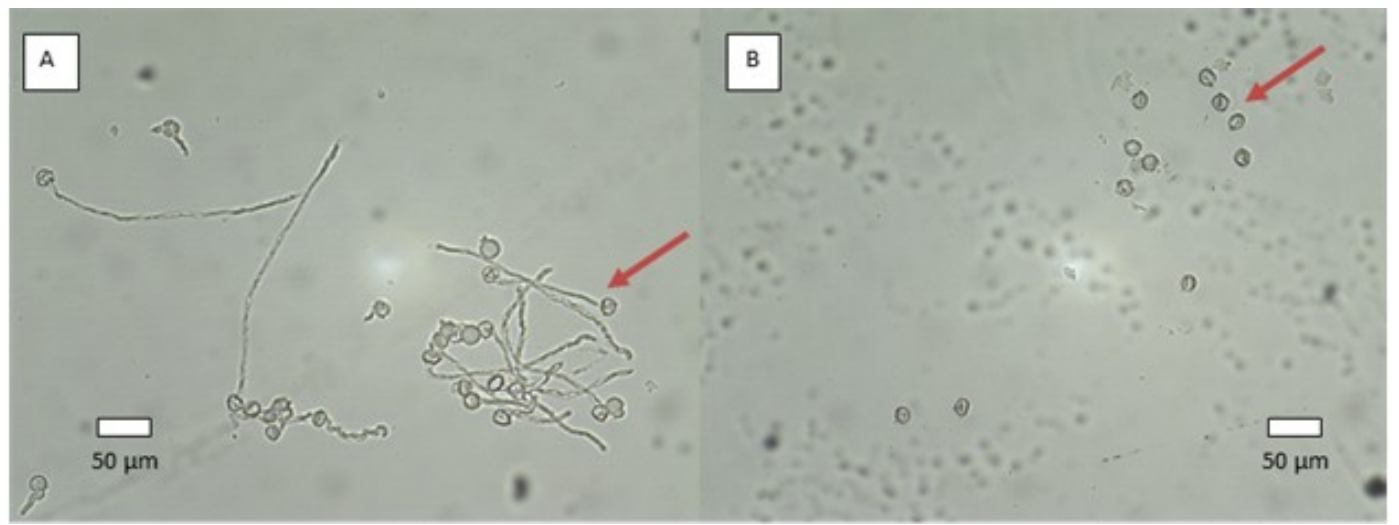

Figure 2. In vitro germinating pollen of $A$. tricolor in $10 \%$ sucrose after 4 hours (100×), (A) pollen tube growth on germinated pollen, (B) Non-germinated pollen

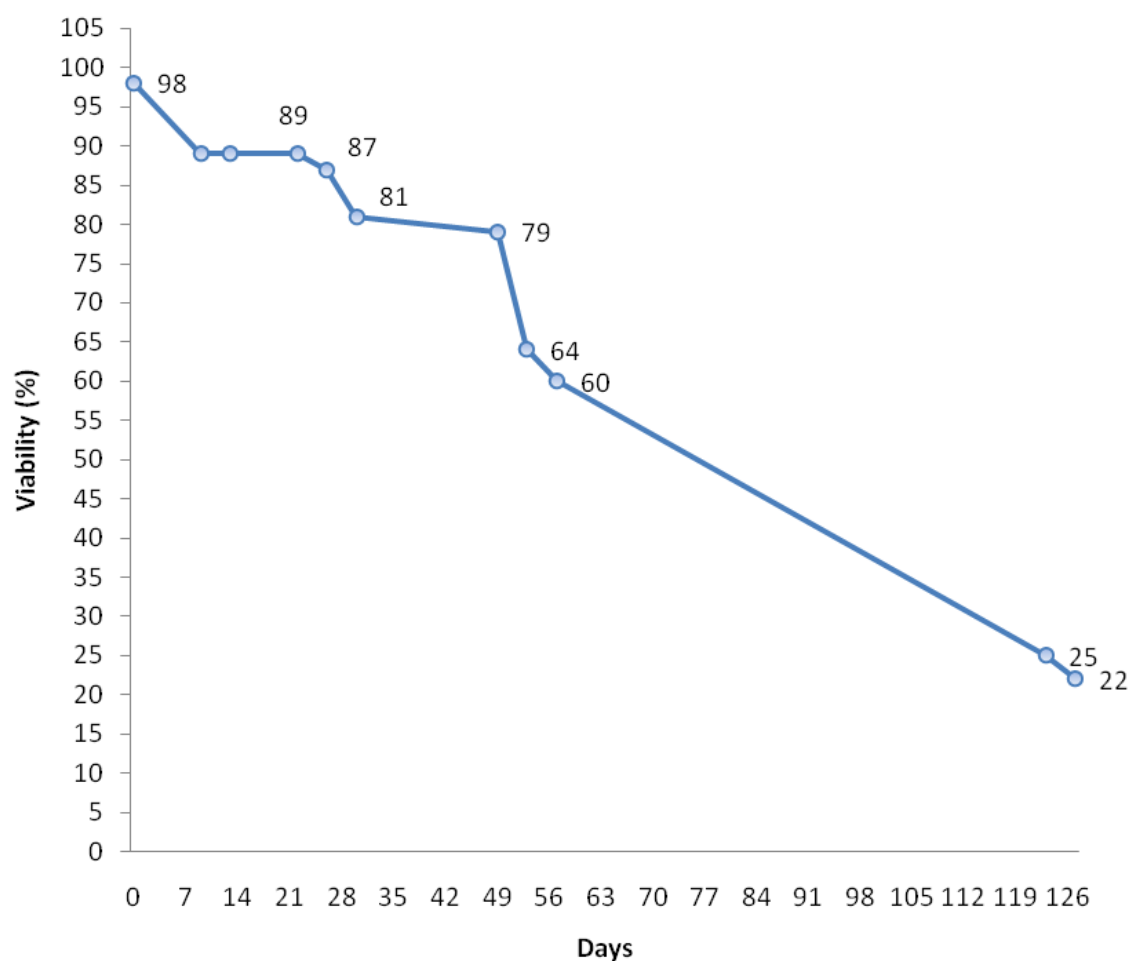

Figure 3. The viability of $A$. tricolor stored pollen until 127 days after anthesis

germination in vitro include a carbon source, boron and calcium, water potential, $\mathrm{pH}$, pollen density, and aeration of culture medium [12]. A wide variety of species of pollen grains have successfully germinated in sugar solutions. Sucrose is probably a better and more commonly used source ofcarbon and energy for pollen than lactose, dextrose, raffinose and several other sugars and sugar derivatives $[16,17]$. In general, pollen grains require water for pollen tube formation and excellent germination has been obtained in sugar media with or without lower percentage of agar.
In a study of pollen germination of Torenia asiatica L., the maximum germination percentage and longest pollen tubes were attained in $15 \%$ sucrose solution [18]. Also in $15 \%$ sucrose concentration, pollen germination percentage has been determined to be $72.90 \%$ for apricot, $57.38 \%$ for sweet cherry and $49.16 \%$ for sour cherry [19]. In another study, pollen grains of Okra successfully germinated in a $20 \%$ sucrose concentration but in $30 \%$ and $40 \%$ sucrose media, pollen germination and pollen tube length declined [11]. In a study of Cherry Laurel (Prunus laurocerasus L.), pollen 
germination rates increased at $15 \%$ sucrose and declined at $20 \%$ sucrose concentration; $10 \%$ sucrose concentration gave the highest germination percentage [9]. Staining tests with 2,3,5-triphenyl tetrazolium chloride (TTC) and iodine potassium iodide (IKI) were used to test the viability of Cherry Laurel pollen, also using in vitro medium containing $0 \%, 5 \%, 10 \%, 15 \%$, and $20 \%$ sucrose to determine the best sucrose concentration for germination [9]. Pollen was well-stained with IKI test and pollen viability estimated with TTC was better, for the best pollen germination rates was in $15 \%$ sucrose.

A study of in vitro pollen germination in Lawsonia inermis Linn. founded that for pollen harvested 3 hours after anthesis, a $10 \%$ sucrose solution resulted in $58 \%$ germination, and a $15 \%$ sucrose solution raised the germination to $72 \%$ [20]. A culture medium containing $0.03 \% \mathrm{Ca}\left(\mathrm{NO}_{3}\right) 4 \mathrm{H}_{2} \mathrm{O}, 0.02 \% \mathrm{Mg}\left(\mathrm{SO}_{4}\right) 7 \mathrm{H}_{2} \mathrm{O}$, $0.01 \% \mathrm{KNO}_{3}, 0.01 \% \mathrm{H}_{3} \mathrm{BO}_{3}, 15 \%$ sucrose and $0.8 \%$ agar, with $\mathrm{pH}$ of 7.0 for Passiflora spp. gave higher percentage of pollen grains germinated [21]; anthesis was founded to be the best time to collect pollen, promoting high viability and germination [21]. The study [14] of in vitro pollen germination in Ricinus communis $\mathrm{L}$. found that pollen collected at anthesis into a $12 \%$ sucrose solution supplemented with $100 \mathrm{ppm}$ boric acid resulted in an $80 \%$ germination percentage and $195 \mu \mathrm{m}$ long pollen tubes.

\section{Pollen viability test after storage}

The application of pollen storage is usually for plant breeding purposes. But also it can be used to retain a batch of pollen in a constant condition over time for genetic, physiological and biochemical studies. Assays for pollen viability can be divided into three general groups based upon (1) pollen staining/ fluorescence, (2) pollen germination, and (3) fruit or seed set [22]. Our studyonly investigated pollen germination

In general, the conditions of storage that influencethe maintenance of pollen germination capacity include relative humidity (R.H.), temperature, and the atmosphere surrounding the pollen. Pollen longevity is decisively affected by the humidity during storage. For most species, the highest viability of pollen in storage is achieved at low relative humidity. The viability of some types of pollen instorage at $0^{\circ} \mathrm{C}$ or $-15^{\circ} \mathrm{C}$, can be extended beyond $1-3$ years if the R.H. is maintained between 10 and 50\% [5].

In our study, pollen germinability stored at $-20^{\circ} \mathrm{C}$ declined progressively over four months. Nevertheless, in vitro germination percentage was still at $22 \%$ after period of time.

The decrease in germination capacity of pollen during storage,as measured by these in vitro tests should be distinguished from the influence of storage to pollen ability to set seed. The critical morphogenetic event in pollen germination is the fulfilment of its ultimate function of discharging male gametes into the embryo sac [23]. This requires a different kind of study

The percentage of germination and tube length after storage at low temperature are reduced in part because temperature affects the rigidity of the pollen tube wall [16]. The major factors that determine pollen viability is temperature and moisture content. Pollen collection techniques sometimes involve short periods of drying to promote anther dehiscence. Based on studies on Chlorophytum comosum (Thunb) Jacq. And Asparagus officinalis L. [22], drying the pollen before storage is often necessary to further lower the moisture content.If the storage humidityiscontrolled,pollen will not become rehydrated during the storage period.

A study of Kiwi fruit [24], showed that pollen grains can be stored for a short period (40 days) in simple environments with reduced temperature (refrigerator or freezer). After 120 days, about $35 \%$ of the pollen grains were still viable if stored at $-18^{\circ} \mathrm{C}$, decreasing to $15 \%$ after 240 days.

The wall of pollen grains contains many enzymes. Before the pollen tubes are formed, the enzymes will readily diffuse into the surrounding medium. The enzyme activity which decrease respiratory substrates will cause the decline of pollen viability in storage. Another factor that supports the viability of pollen during storage is the conversion of sugars into organic acids, which relates to the intracellular rates of respiration.

Many observations have confirmed that stored pollen requires higher concentrations of sugar for normal germination than fresh pollen. Increasing sucrose concentration can produce optimal germination and this has been attributed to a decrease in pollen permeability $[5,16]$. The reduction of germination capacity under storage conditions can be interpreted as an inactivation of enzymes and metabolic substrates essential for germination. An accumulation of secondary metabolic products, such as organic acids during storage, may inhibit subsequent pollen growth.

In vitro germination tests are not always conclusive indices of pollen growth potential after storage. There 
are results indicating that stored pollen that shows a reduction in germination ability by in vitro tests may not always be non-viable [5].

In the present study it was observed that the percentage of pollen germination declined with increased duration of storage in $10 \%$ sucrose. Based on other studies [6], we hypothesis that adding boron to storage media could maintain the viability of stored pollen over a longer period of time. The decrease in pollen viability over time may be related to the loss of water permeability by intine during storage. In the absence of boron, pollen tubes show abnormalities like coiling and bursting. Boron impacts pollen germination and pollen tube growth in three ways: it promotes absorption of sugars; it increases oxygen uptake; and also it is involved in the synthesis of pectic material for the wall of the actively growing pollen tube $[6,25]$. The key factor in achieving successful germination and to manipulate pollen tube growth is the osmolarity of pollen germination solution [26]. Further research needs to be carried out to see if these effects of boron also found in A. tricolor pollen.

\section{CONCLUSION}

In this study with the species $A$. tricolor Hook., a10\% sucrose germinating solution was used as the medium for determining the germination percentage of pollen collected at different times around the event of floral anthesis. The highest germination percentage was found on the day of anthesis (96\%). Before anthesis and in the days after anthesis, pollen collected had a lower germination until at five days after anthesis, germination had dropped to less than $6 \%$. Thus the day of anthesis was selected as the day on which to collect pollen for testing the effect of storage duration on pollen viability. Germination of pollen was at its highest at the time of anthesis and storing this pollen at $-20^{\circ} \mathrm{C}$ resulted in significant step wise reductions in pollen viability until by 127 days after anthesis the germination percentage had dropped to $22 \%$.

\section{ACKNOWLEDGMENT}

Authors sincerely thank to the Center for Plant Conservation, Bogor Botanic Gardens - LIPI, for providing the necessary facilities to carry out the present work.

\section{REFERENCES}

1. Denduangboripant J, Cronk QCB (2000) High intraindividual variation in internal transcribed spacer sequences in
Aeschynanthus (Gesneriaceae): implications for phylogenetics. Proceedingsof the Royal Society Biological Sciences 267 (1451): 1407-1415. doi: 10.1098/rspb.2000.1157.

2. Middleton DJ (2007) A revision of Aeschynanthus (Gesneriaceae) in Thailand. Edinburgh Journal of Botany 64 (3): 363-429. doi: 10.1017/S0960428607004878.

3. Rahayu S, Wawangningrum H.and Garvita R.V. (2015) Morphological characteristic and flower development of Aeschynathus tricolor Hook. (Gesneriaceae). Berita Biologi 14 (3): 203-211.

4. Singapore Garden Society. 2015. Aeschynanthus : A Taxonomic Study. http://www.gardensingapore.org/. Accessed: December 23, 2015.

5. Stanley RG, Linskens HF (1974) Pollen, Biology Biochemistry Management. Berlin, Spriger-Verlag.

6. Ahmad S, Rana A, Sharma R, Agnihotri RK (2012) Effect of different media and boric acid on pollen germination and tube of Tribulus terrestris - a traditional medicinal plant. International Journal of Pharmaceutical Sciences Review and research 13 (2): 77-79.

7. Volk GM (1995) Collecting pollen for genetic resources conservation. In: Guarino L, Rao VR, Reid R, eds. (1995) Collecting plant genetic diversity: Technical guidelines.CAB International. Rome, Bioversity International. pp: 110

8. Bellusci F, Musacchio A, Stabile R, Pellegrino G (2010) Differences in pollen viability in relation to different deceptive pollination strategies in Mediterranean orchids. Annals of Botany 106: 769-774. doi:10.1093/aob/mcq164

9. Sulusoglu M, Cavusoglu A (2014) In vitro pollen viability and pollen germination in Cherry Laurel (Prunus laurocerasus L.). The Scientific World Journal 2014 (2014): 17. doi: $10.1155 / 2014 / 657123$.

10. Kelly JK, Rasch A, Kalisz S (2002) Brief communication: A method to estimate pollen viability from pollen size variation. American Journal of Botany 89 (6): 1021-1023. doi: 10.3732/ajb.89.6.1021.

11. Baloch MJ, Lakho AR, Bhutto H, Solangi MY (2001) Impact of sucrose concentration on in vitro pollen germination of Okra, Hibiscus esculentus. Pakistan Journal of Biological Sciences 4 (4): 402-403. doi: 10.3923/pjbs.2001. 402.403

12. Rihova L, Hrabetova E, Tupy J (1996) Optimization of conditions for in vitro pollen germination and tube growth in potatoes. International Journal of Plant Sciences 157 (5): 561-566.

13. Kamrani R (2012) Study on pollen germination and pollen tube growth of five Iranian Apricot cultivars on in vitro conditions. International Conference on Applied Life Sciences (ICALS), Nejadkoorki F (Ed). pp: 299-302.

14. Mudi MD, Mondal S (2014) Influence of some nutrients 
on in vitro pollen germination of Ricinus communis $\mathrm{L}$. Cibtech Journal of Bio-Protocols 3 (3): 15-20.

15. Kakani VG, Prasad PVV, Craufurd PQ, Wheeler TR (2002) Response of in vitro pollen germination and pollen tube growth of groundnut (Arachis hypogaea L.) genotypes to temperature. Plant, Cell and Environment 25: 1651-1661.

16. Vasil IK (1987) Physiology and culture of pollen. In: Giles KL, Prakash J eds. (1987) International review of cytology (Vol. 107) Pollen: Cytology and development. Florida, Academic Press.

17. Ali T, Ali SI (1996) Effect of sugar concentration on pollinium germination in some members of Asclepiadaceae. Pakistan Journal of Botany 28 (2): 161-165.

18. Bolat I, Pirlak L (1999) An investigation on pollen viability, germination and tube growth in some stone fruits. Journal of Agriculture and Forestry 23: 383-388.

19. Nambudiri EMV, Thomas MK (1974) Effects of chemicals on the germination of pollen grains of Torenia asiatica Linn. The Great Basin Naturalist 34 (1): 71-81.

20. Mondal S, Ghanta R (2012) Studies on in vitro pollen germination of Lawsonia inermis Linn. Advances in Bioresearch 3 (3): 63-66.

21. Soares TL, de Jesus ON, Santos-Serejo JAD, de Oliveira AJ (2013) In vitro pollen germination and pollen viability in passion fruit (Passiflora spp.). Revista Brasileira de Fru- ticultura 35 (4): 1116-1126. doi: 10.1590/S010029452013000400023.

22. Mondal S, Ghanta R (2012) Studies on in vitro pollen germination of Lawsonia inermis Linn. Advances in Bioresearch 3 (3): 63-66.

23. Gudadhe SP, Dhoran VS (2012) Observations on pollen viability, in vitro pollen germination and pollen tube growth in Chlorophytum comosum (Thunb) Jacq. and Asparagus officinalis L. International Journal of Current Research 4 (7): 22-27.

24. Towil LE (1985) Low temperature and freeze-/vacuumdrying preservation of pollen. In Cryopreservation of plant cells and organs (KK Kartha Eds). United States, CRC Press.

25. Borghezan M, Clauman AD, Steinmacher DA, Gueraa MP, Orth AI (2011) In vitro viability and preservation of pollen grain of Kiwi (Actinidia chinensis var. Deliciosa (A. Chev.) A. Chev). Crop Breeding and Applied Biotechnology 11: 338-344. doi: 10.1590/S1984-70332011000400007.

26. Patel RG, Mankad AU (2014) In vitro pollen germinationa review. International Journal of Science and Research 3 (5): 304-307.

27. Stone LM, Seaton KA, Kuo J, McComb JA (2004) Fast pollen tube growth in Conospermum species. Annals of Botany 93: 369-378. doi:10.1093/aob/mch050. 